\title{
Comparative Assessment of Single Piece and Fir Tree Based Spoke Type Rotor Designs for Low Cost Electric Vehicle Application
}

\author{
M. Kimiabeigi, R. Long, J. D. Widmer, Y. Gao
}

\begin{abstract}
Permanent magnet motors with ferrite magnets may be applicable to demanding electric vehicle ( $\mathrm{EV})$ applications, provided that designs with high power density and efficiency, as well as high resistance to demagnetization are developed. One rotor topology that allows meeting those challenges is a design with a so-called spoke arrangement of the magnet poles. Although, a spoke type rotor topology is widely known, the influences of the rotor mechanical design on the electromagnetic performance has, largely, been overlooked, while a comparison of different feasible design solutions has not been provided to date. In this paper, a novel spoke type traction motor using ferrite magnets and based on a single piece rotor topology has been presented. The design is based on a coupled structural electromagnetic optimization, where the key design features, influencing the structural stress and the electromagnetic torque density have been explained. This design is, further, compared against a previously disclosed fir tree spoke type rotor solution, which has been designed for the same set of geometrical and output requirements. Through the comparisons, and for the first time, it is shown that the two alternative spoke type designs, show significant differences in performance, including torque density, efficiency, and demagnetization.
\end{abstract}

Index Terms - Demagnetization, Efficiency, Electric Vehicle (EV), Ferrite Magnets, Fir-Tree, Single Piece Rotor, Spoke.

\section{INTRODUCTION}

$\mathrm{P}$ ermanent magnet motors are amongst the best candidates for applications with high power density and efficiency requirements, such as electric vehicle (EV) traction [1], [2], [3], [4]. This superiority is due to the high energy dense permanent magnets which reduce the required level of electric loading and the associated winding losses for a given power

This work is funded by Innovate UK under Grant 110130.

M. Kimiabeigi and J. D. Widmer are with Newcastle University, Newcastle Upon Tyne, NE17RU UK (e-mail: mohammad.kimiabeigi@ncl.ac.uk). R. Long and Y. Gao are with Tata Steel, UK (email: ray.long@tatasteel.com). density [5]. Amongst permanent magnets, those made of rare earth elements, such as Neodymium Iron Boron $(\mathrm{NdFeB})$, may contribute to designs with highest power densities (owing to high remanent flux density, $B_{r}$ ), and best demagnetization resistance (owing to the high intrinsic coercivity, $H_{c j}$ ). However, due to the high and volatile price of these magnets during the last decade, magnets with less or no rare earth elements, such as ferrite magnets, have gained some popularity [6], [7], [8], [9]. The main design challenges with these alternative magnets is to achieve high level of power density, while mitigating the demagnetization risk under the field weakening and short circuit conditions, [8]. To meet the high power density requirement, designs with high contribution of reluctance torque, as well as flux concentration effect, such as Interior Permanent Magnet (IPM) with U-shape [10], [11], V shape [12], LC shape [13], and spoke magnet topologies [7], [8], [14], [15], and [16] can be employed; furthermore, few high torque density dual stator topologies and axial flux designs have been reported [17], [18]. To meet the demagnetization resistance criterion several approaches can be followed, such as: a) burying the magnets deep in the rotor, while tapering the flux barriers toward the airgap [10], or extending the rotor pole tips to bypass the demagnetization field [8], b) reducing the number of turns and thickening the magnets in the direction of magnetization [7], [8], c) increasing the end winding leakage ratio by shortening the stack length and increasing the magnetic saturation, [19], and d) applying analytical techniques to diagnose and prevent demagnetization during the motor operation [20]. In terms of the stator windings, both distributed configuration [7], [8], and a concentrated type [14], [15] can be employed. Even though the latter may benefit from shorter and more isolated (nonoverlapping) end windings, the former may achieve higher power densities owing to the significant contribution of the reluctance torque.

One major aspect of design for EV application is to ensure the structural integrity of the rotor under high speed operation and for the entire life time of the vehicle [21]. On this basis, the spoke type rotor can be composed of two parts, including the ferromagnetic poles (providing the magnetic flux path) and the non-magnetic support (providing mechanical support), which are connected via a fir-tree feature, [7], [22]. 
Alternatively, the rotor may be consisted of a single ferromagnetic piece which provides the magnetic and mechanical support role, simultaneously, [14]. In this case, an appropriate flux barrier configuration in the rotor must be adopted to limit the flux leakage through the rotor yoke regions. Although the fir-tree based design may provide higher power density owing to the non-magnetic support region (thereby lower leakage of permanent magnet flux), it may incur additional costs due to the extra components as well as the further features and assembly costs to affix the two parts of the rotor.

Although few designs based on both aforementioned spoke rotor topologies have been tried, the implications of the two distinctive mechanical designs on the electromagnetic performance has been overlooked by the literature, where no detailed comparative assessment of the two spoke type configurations has been reported to date. In this paper, a high speed- high power density spoke type design based on a single piece rotor topology, and considering both the magnetic and structural requirements of a high performance low cost EV application is presented. The performance of this design is compared against a fir-tree based alternative solution targeting the same sets of requirements and constraints, [8] and [21]. Based on these comparisons, the pros and cons of the two design solutions, in terms of the power density, efficiency, demagnetization and cost, are discussed. The original contributions of this paper can be summarized as follows: a) A high performance traction motor design based on low cost ferrite magnets, and a single piece spoke type rotor topology, is presented; the design is derived based on an innovative stress-constrained mass minimization technique (novel in the context of an electrical machine design application), coupled with a proposed generic topology to maximize the electromagnetic performance. b) For the first time, two alternative spoke type rotor designs (optimized for the same geometrical and output requirements) have been compared in details, highlighting the significant influence of the intrinsic mechanical design differences on the electromagnetic performance and the overall motor design characteristics.

\section{II.BACKGROUND AND MOTIVATION FOR STUDY}

The current paper is related to the design of a ferrite based, low cost high performance electric motor for an all-electric vehicle project, the requirements of which are listed in Table I. In [8], a spoke type design with a distributed winding is proposed and shown to marginally meet the requirements in Table I; the major dimensions of this design are given in Table II. Despite the high performance of the design in [8] and [21], the rotor is made of two parts including the magnetic rotor pole segments and the non-magnetic rotor support, which are coupled together via a so-called fir tree feature. Due to the additional cost of the rotor support material, and the extra provisions required to, safely, affix the support and the pole segments, the fir-tree rotor design might lose some of its performance per cost competitiveness. Therefore, in the present paper, a simpler rotor topology consisting of a single ferromagnetic piece has been investigated. An illustrative cost comparison between the two alternative rotor designs has been provided in Appendix I. In the following sections, the design and performance of the single piece rotor topology in terms of the electromagnetic and structural performance are addressed and evaluated against both the target requirements and the design with the fir-tree based rotor topology, and conclusions are drawn.

TABLE I

DESIGN REQUIREMENTS FOR THE FERRITE BASED TRACTION MOTOR.

\begin{tabular}{|l|l|}
\hline $\begin{array}{l}\text { Gross volume (including cooling and end } \\
\text { winding) }\end{array}$ & $<14$ liter \\
\hline Peak power density per motor volume & $>6 \mathrm{~kW} /$ liter \\
\hline Continuous power density per motor volume & $>4 \mathrm{~kW} /$ liter \\
\hline Base to top speed ratio & $3000 \mathrm{rpm}: 15000 \mathrm{rpm}$ \\
\hline Maximum winding temperature & $180{ }^{\circ} \mathrm{C}$ \\
\hline Available water cooling options & Only via outer stator frame \\
\hline Demagnetization withstand capability & Against 3 -phase short circuit \\
\hline Ferrite,FB9B, Br at $20^{\circ} \mathrm{C} / \mathrm{Hcj}$ at $20^{\circ} \mathrm{C}$ & $0.43 \mathrm{~T} / 370 \mathrm{kA} / \mathrm{m}$ \\
\hline Maximum achievable inverter current, Ipk & $420 \mathrm{Arms}$ \\
\hline Minimum available DC link voltage & $400 \mathrm{~V}$ \\
\hline
\end{tabular}

TABLE II

MAJOR DIMENSIONS OF THE SPOKE TYPE DESIGN IN [8].

\begin{tabular}{|l|l|}
\hline Stator outer diameter $(\mathrm{mm})$ & 205 \\
\hline Rotor outer diameter $(\mathrm{mm})$ & 140 \\
\hline Stack length $(\mathrm{mm})$ & 195 \\
\hline Airgap $(\mathrm{mm})$ & 0.5 \\
\hline
\end{tabular}

\section{DESIGN AND ANALYSIS}

\section{A. Power Density and Structural Performance}

Due to the same packaging requirements as the fir-tree based design and to highlight the differences on the rotor part design only, the single piece rotor design is based on the same stator and rotor dimensions as provided in Table II. To maximize the output torque of the motor, while maintaining the rotor stress below the limits chosen for the rotor strength, deformation and durability (based on M270-35A non-grain oriented electrical steel), a combined electromagnetic and structural optimization of the rotor was performed, as a result of which the rotor topology in Fig.1(a) was obtained.

With regards to the magneto-structural optimization, a linear-elastic, multi-objective optimization was performed, which targeted at achieving a minimum rotor pole mass, at a specified maximum stress and radial deflection limit, as well as a set minimum thickness of the rotor bridges to respect the manufacturing feasibility, Fig. 2. This topological optimization is based on a so-called stress constrained mass minimization technique, which although known to the structural and civil engineering, is not commonly applied in the context of electrical machine design; a more detailed description of the technique has been provided in Appendix II. The structural optimization was, further, guided with the electromagnetic simulations, based on which the flux barriers were concentrated in two proposed generic zones, namely the two main cavities beside and underneath the magnets, where particular attention was paid to maximize the reluctance of the magnetic leakage path, and leaving the q-axis flux path undisturbed (to maximize the saliency), Fig. 1(b). The topology solution was, then, evaluated by a non-linear-plastic 
simulation, where finer design adjustments have been implemented. On this basis, the optimizations can be said to consist of two objectives, namely mass and torque/ power density. With regards to the torque/ power, only two corner points corresponding to the peak torque at base rotor speed, and peak power at top rotor speed have been considered, while for each calculation the current advance angles have been fine tuned to achieve a maximum/ optimal torque/ power value.

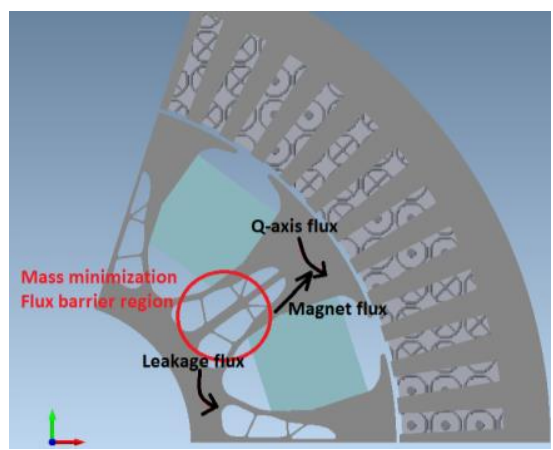

(a)

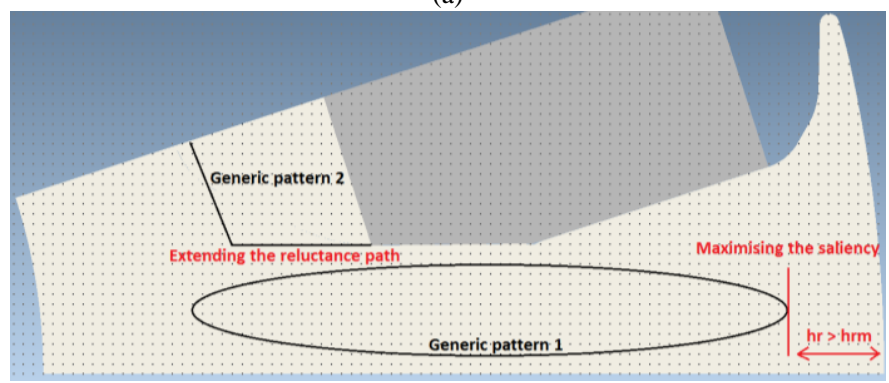

(b)

Fig. 1. The proposed rotor topology for high speed high torque density traction application. (a) Topology. (b) Illustration of rotor mass minimization.

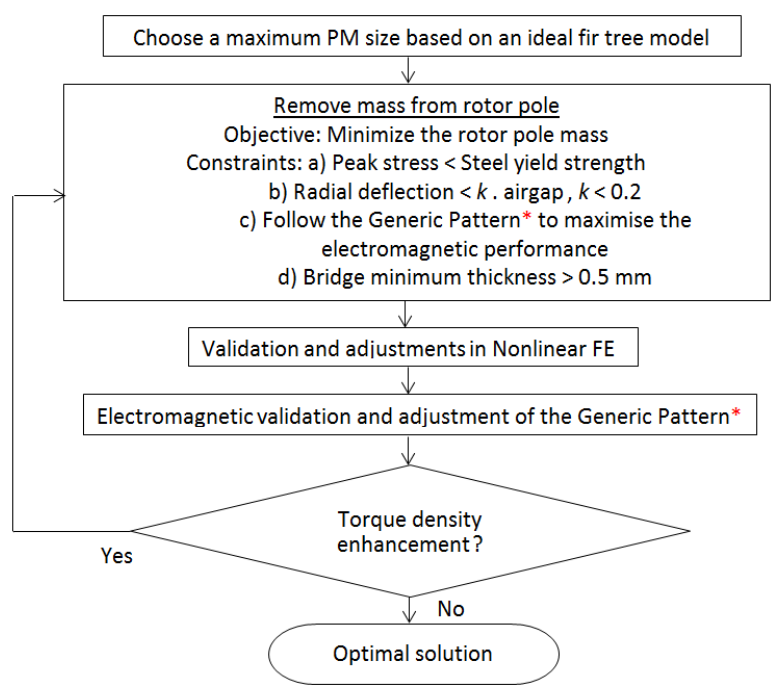

Fig. 2. Optimization algorithm for the single piece spoke rotor. * See Fig. 1.

The stress distribution in the rotor for the fir tree based design in [8] and the optimized single piece topology in Fig.1, have been compared in Fig. 3, where it is realized that for a same rotor pole material, the fir tree design may outperform the single piece design by about $19 \%$ lower peak stress. Furthermore, the magnetic field distribution in the single piece rotor design and the peak torque at base and top speed have been assessed in 2D FE, Figs. 4 and 5, based on which it is realized that due to a higher magnetic loading (lower magnet leakage) the fir tree design outperforms the single piece rotor by providing $\sim 20 \%$ higher peak torque and power density at the base and top speed.

With regards to the magnet contribution to the BEMF under no-load conditions and the peak torque, it should be noted that due to the presence of the armature d-axis flux in the bridges and the intensified magnetic saturation, Figs. 4(a) and (b), the magnet leakage is lower under loaded conditions; thereby a larger contribution of the magnets to the peak torque compared to the BEMF, and a larger deviation between the $\mathrm{BEMF}$ and the peak torque must be envisaged.

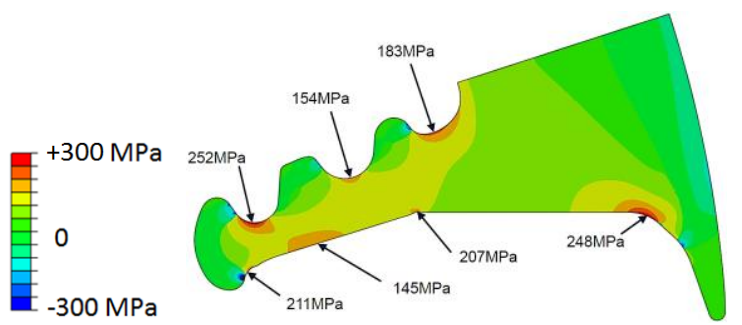

(a)

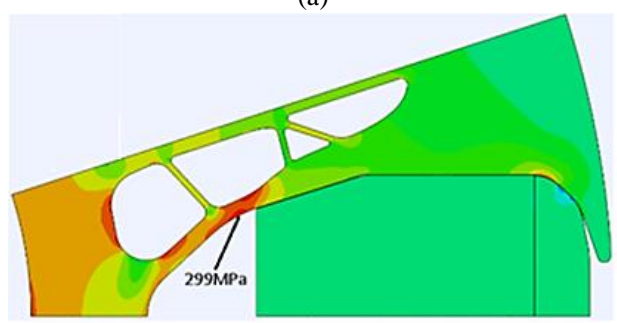

(b)

Fig. 3. Stress distributions at $15 \mathrm{krpm}$ for fir-tree and single piece rotor design. (a) Fir tree based rotor pole. (b) Single piece rotor.
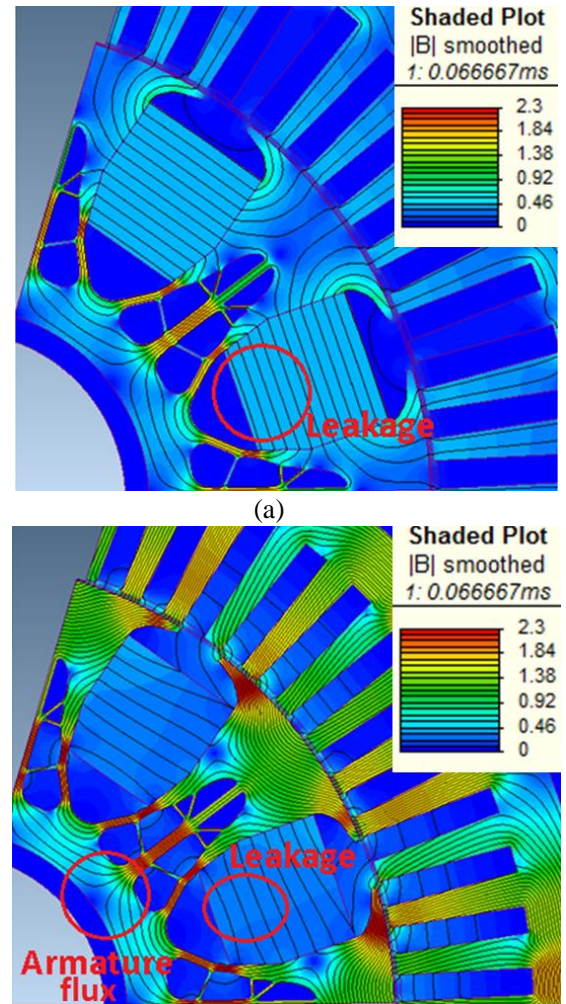

(b)

Fig. 4. Flux density in the single piece rotor design, and illustration of saturation impact on the magnet leakage. (a) No load. (b) Peak load, 3 krpm. 


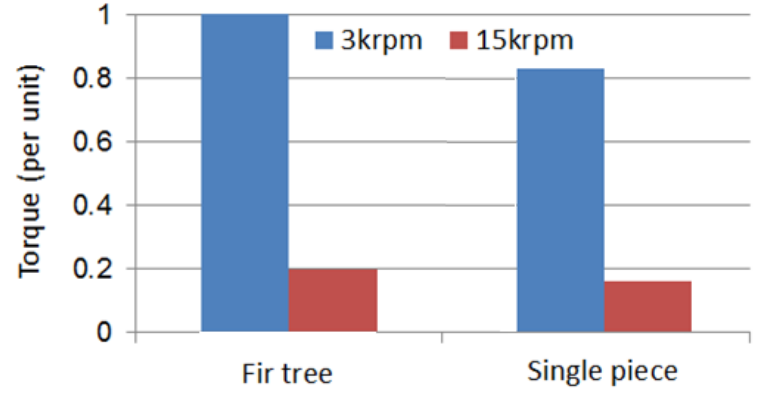

Fig. 5. Comparison of the fir tree and single piece rotor in terms of peak torque at base and top speed

\section{B. Demagnetization}

The demagnetization of the ferrite magnets during the field weakening or, more critically, under short circuit faults is one of the major risks of the ferrite based traction motors. The currents of the single piece design under a 3-phase short circuit fault (occurring after one full electrical period of regenerative peak torque operation) have been simulated in 2D FE and shown in Fig. 6. From Fig. 6, it is realized that the peak short circuit current is about $160 \%$ of the $I_{p k}$, which is about the same amplitude for the fir-tree based design in [8].

The field strength, $\mathrm{H}$, distribution in the rotor and under the worst instant during the 3 - phase short circuit fault (i.e. when $I_{b}$ reaches its peak value in Fig. 6), has been simulated for both the single piece rotor and the fir tree design in $2 \mathrm{D} F E$, and the results are shown in Fig. 7. The red areas indicate the regions where the $\mathrm{H}$ field is greater than the intrinsic coercivity of the FB9B grade Ferrite magnet at $20^{\circ} \mathrm{C}$, and therefore complete demagnetization may be expected. From Figs. 7 (a) and (b), it can be realized that, even though due to the similar rotor topology near the airgap region, the demagnetization risk for the two designs is identical, for the inner parts of the rotor the location of the maximum field and thereby risk of demagnetization is different. In this regard, for the single piece rotor lamination the maximum demagnetization field occurs near the magnet bottom edge with highest flux concentration, whereas for the fir-tree based model the maximum field occurs further away from the magnet and in the pole shoe tips.

For a clearer comparison of the two designs and to assess the performance under more severe demagnetization conditions such as asymmetrical short circuits, [23], a higher demagnetization current, equal to $400 \%$ of the $\mathrm{I}_{\mathrm{pk}}$, has been applied, and the $\mathrm{H}$ distribution has been simulated and shown in Figs. 8(a) and (b). From Figs. 8(a) and (b), it can be realized that the demagnetization resistance of the single piece rotor model may, significantly, exceed that of the fir tree model, as the inner magnet regions are prone to lower demagnetization risk. This is mainly due to the ferromagnetic leakage flux path adjacent to the inner part of the magnets in the single piece rotor model in contrast to the air void leakage flux path in the fir tree based model; where as a result of the lower magnetic reluctance path in the single piece model, the demagnetization field is better bypassed and the magnets are less affected.

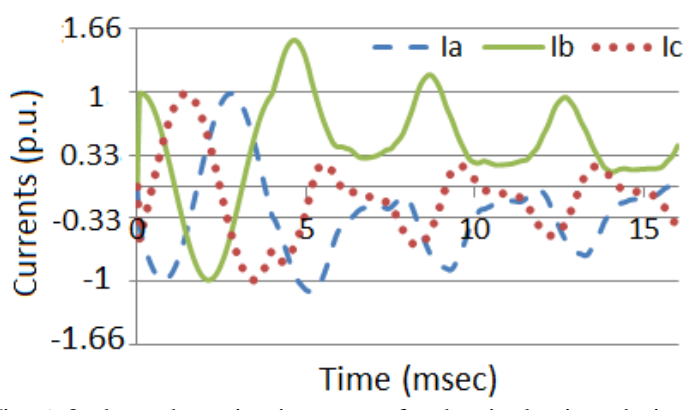

Fig. 6. 3-phase short circuit currents for the single piece design.

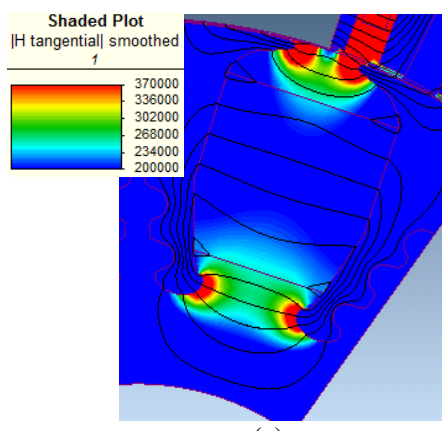

(a)

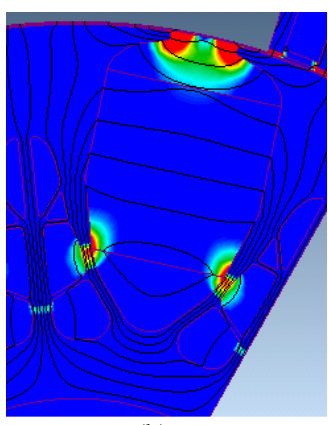

(b)
Fig. 7. Demagnetization risk assessment (H distribution) under $160 \%$ Ipk in negative d-axis location and FB9B magnets. (a) Fir-tree rotor design. (b) Single piece rotor design.

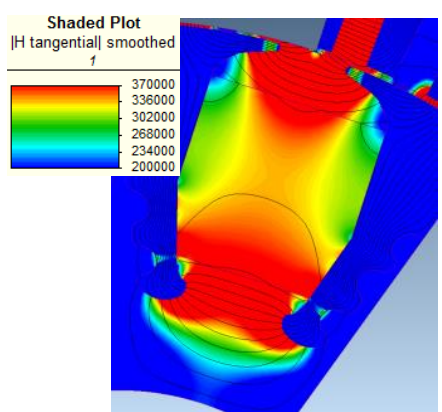

(a)

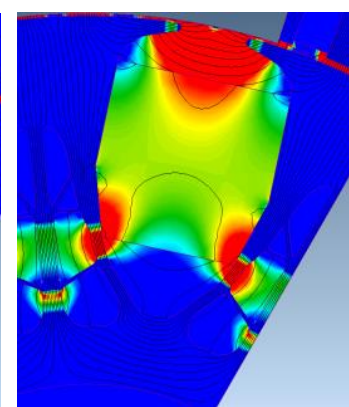

(b)
Fig. 8. Demagnetization risk assessment (H distribution) under $400 \%$ Ipk in negative d-axis location and FB9B magnets. (a) Fir-tree rotor design. (b) Single piece rotor design.

\section{Loss and Efficiency}

To compare the efficiency of the single piece rotor model against that of the fir tree model, the winding and iron losses under whole range of torque-speed operating points have been calculated. The iron loss calculation has been based on the open circuit and short circuit modelling in FE 2D and using the computationally efficient technique disclosed in [24] and [25]. With regards to the winding DC loss, a copper winding with slot fill factor of $45 \%$ and at $120{ }^{\circ} \mathrm{C}$ has been considered. The windings AC loss was, also, calculated in FE 2D and the maximum $\mathrm{AC}+\mathrm{DC}$ to $\mathrm{DC}$ loss ratio (at $15000 \mathrm{rpm}$ ) was obtained equal to 1.4 for both rotor designs. Due to the similar $\mathrm{AC}$ loss factor for the two rotor designs and its relatively small value for the most of the operating speed range, only the DC part of the winding loss has been included in the efficiency map calculations, Fig. 9.

Based on Fig. 9, the peak efficiency of the fir tree model is about 3\% higher than the single piece model. This efficiency superiority covers the majority of the torque-speed envelope, 
including the two key operating points at which the vehicle and the motor will most frequently operate (one corresponding to the urban driving, and one corresponding to the highway cruising). To explain the difference between the efficiency map of the two designs, the stator currents associated with the efficiency maps in Fig. 9, have been calculated (based on maximum torque per ampere function and using an optimal advance angle at each operating point) and shown in Fig. 10. Comparing Fig. 10 to Fig. 9, it can be realized that due to the lower magnetic loading in the single piece design (due to higher magnet leakage and lower magnet utilization), a higher current loading (resulting in higher winding loss) is required to achieve the same level of torque and power at each operating point. Furthermore, due to the lower BEMF levels in single piece model, lower field weakening and d-axis currents are required at higher speed range. As a result, the efficiency (comparing to the fir tree design) is slightly improved at the high speed corner of the torque-speed spectrum.

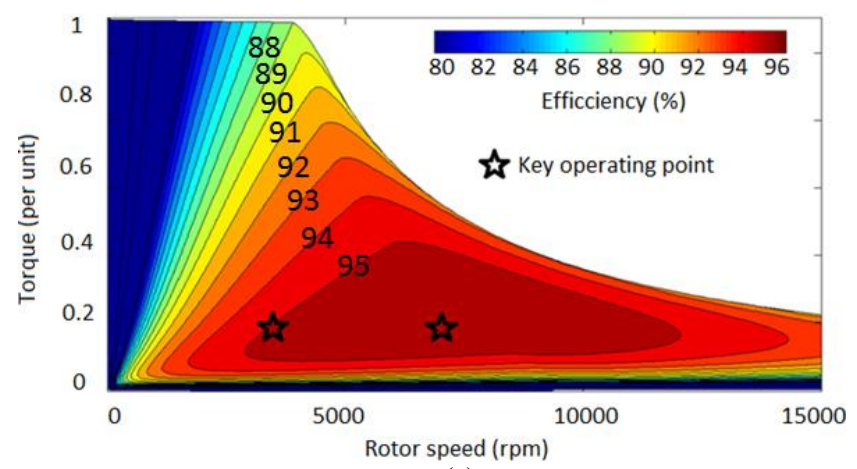

(a)

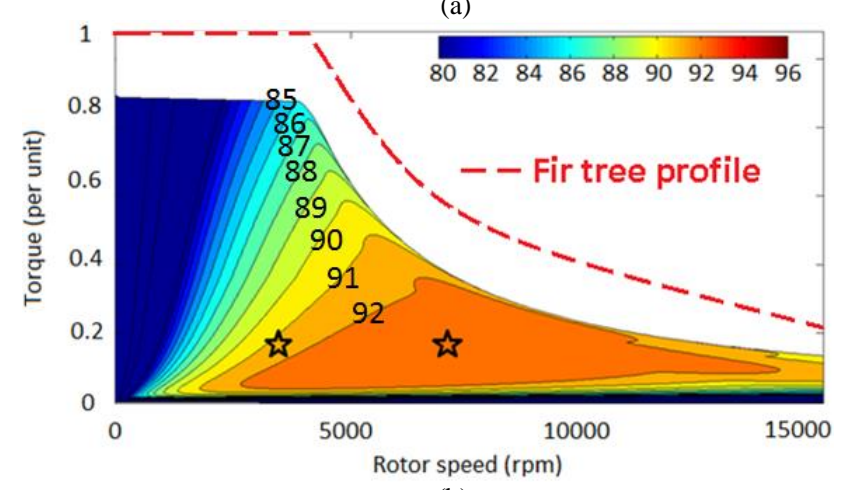

(b)

Fig. 9. Efficiency map for complete torque-speed profile. (a) Fir tree based model. (b) Single piece model.

Finally, with regards to the iron losses in the rotor, it is worth mentioning that the two rotor designs show only minor differences (up to maximum difference of $20 \%$ ) at different operating points. However, the effect of manufacturing on the lamination B-H properties is expected to be more severe in case of the single piece rotor design (due to higher number of cavities and thinner bridges in the lamination), which requires a detailed prototype level investigation.

\section{PRototype test}

To validate the theoretical findings, a prototype with one fifth of the original stack length and including only two coils belonging to one of the phases according to Fig. 11, has been constructed. To allow for a one to one comparison to the fir tree design in [8], a similar lamination material, as well as stator and winding lay-out has been used. With regards to magnets, the Ceramic 8 type in [8] was replaced by stronger FB9B grade, Table I, while the performance of the fir tree design was, also, re-calculated by replacing and employing the FB9B magnet type.

The BEMF test results for the two rotor designs have been compared together and to the FE 2D simulations, in Fig. 12. From Fig. 12, it is realized that the magnetic loading of the single piece design is lower than that of the fir-tree based design, which confirms the difference between the efficiency maps of the two, based on the required current loading explanation given in Section III. C.

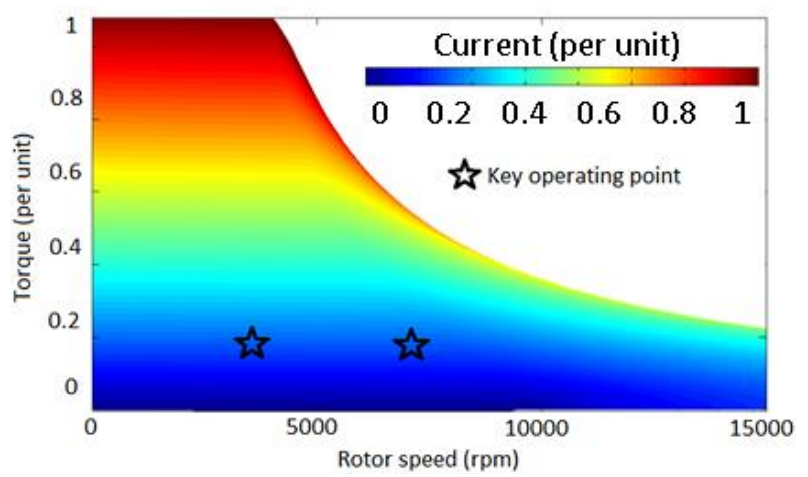

(a)

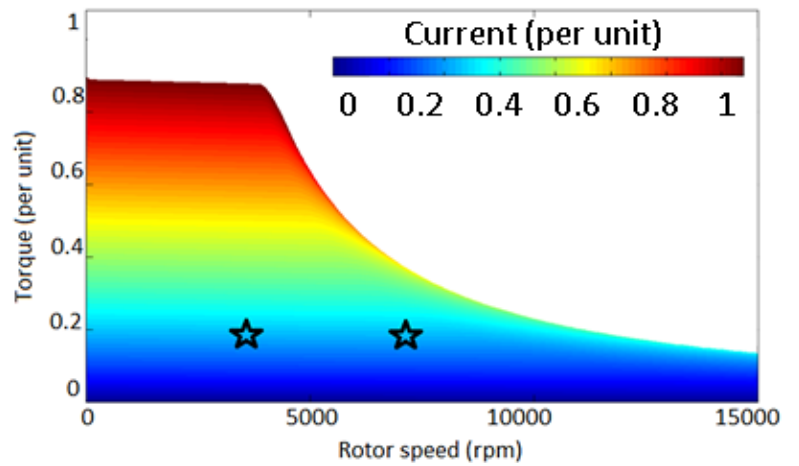

(b)

Fig. 10. Stator line current. (a) Fir tree based model. (b) Single piece model.

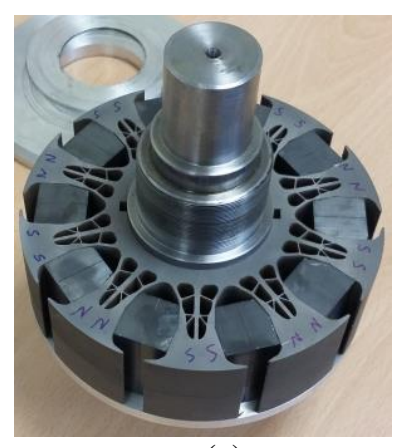

(a)

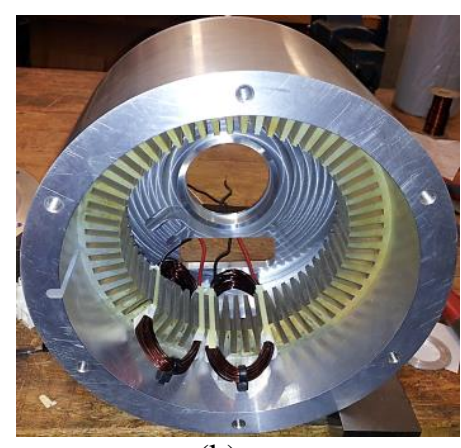

(b)
Fig.11. Simplified prototype motor. (a) Rotor and magnets, (b) Stator, coils and custom built housing without cooling, 


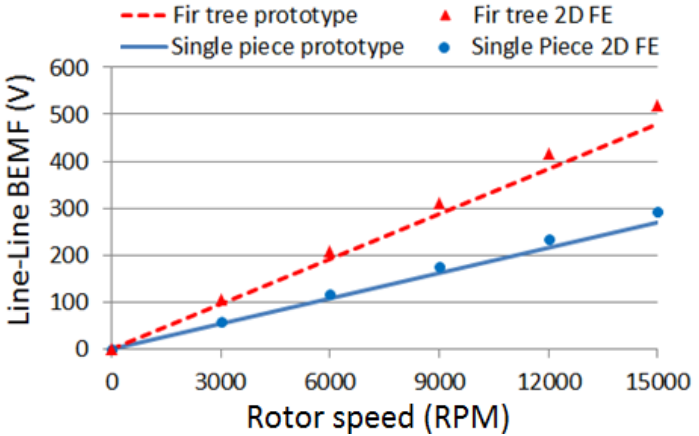

Fig. 12. BEMF vs. rotor speed comparison of the fir-tree and single piece rotor designs.

The static torque of the two designs against zero to maximum current was measured using a rotary table and a torque transducer set up shown in Fig. 13. Based on the test and FE 2D results in Fig. 14, it is realized that for both designs the prototype torque is lower than FE 2D predictions, which can be attributed to the 3D effects as well as the deviation of the material data from the modelling assumptions. Furthermore, the test results confirm the FE predicted difference between the two designs in terms of the torque density, indicating a peak torque gap of less than $20 \%$. Comparing the peak torque values of the two rotor designs against the BEMF, Figs. 14 and 12, and confirming the explanation in Section III.A, it can, also, be noted that the performance gap between the two designs under the loaded conditions is smaller than that under the no-load, this being due to the higher magnetic saturation under the loaded conditions, resulting in lower magnet leakage and higher actual magnetic loading compared to the no-load conditions. Finally, it should be addressed that due to the additional d-axis leakage inductance in the single piece design compared to the fir tree, the former possesses a lower saliency and reluctance torque contribution; this additional d-axis flux leakage in the single piece design, also, leads to an increased and similar voltage rating as the fir tree design (despite the lower BEMF in the former) which rules out the possibility of a further torque enhancement via a turn increase.

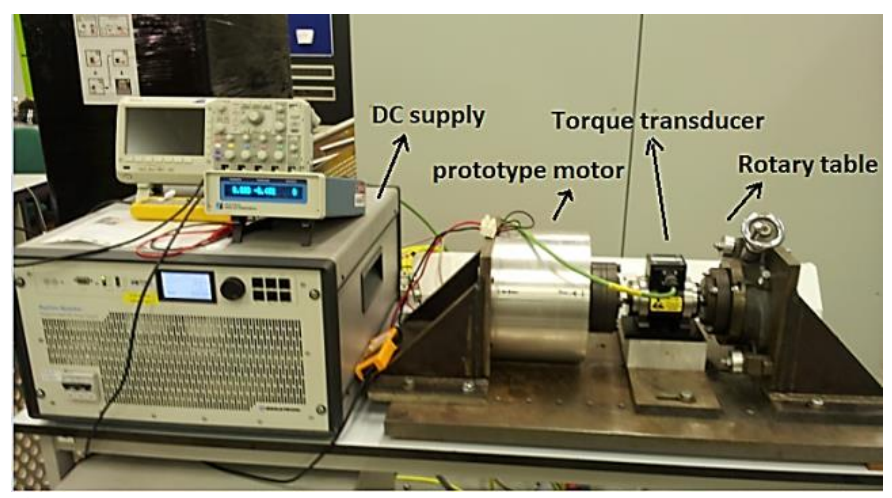

Fig.13. Prototype test set-up.

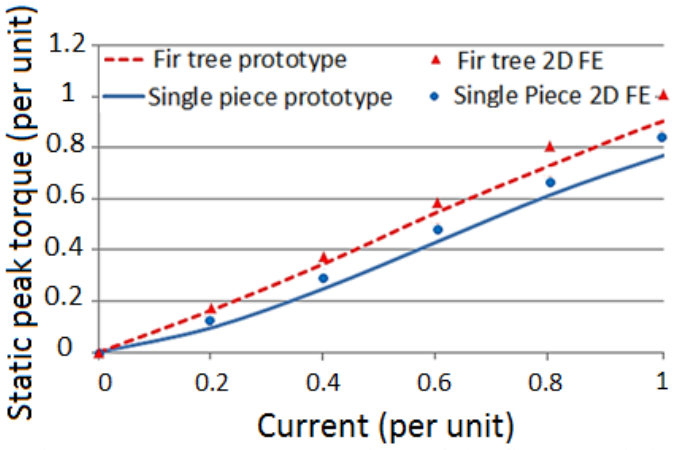

Fig. 14. Static torque vs. current comparison of the fir-tree and single piece rotor designs.

The demagnetization resistance capability of the single piece rotor design has been tested (at $20^{\circ} \mathrm{C}$ room temperature) by injecting $160 \%$ and $400 \%$ of the peak rated current in the negative d-axis position, while the targeted magnets were chosen to be distant by at least one unaffected pole in between, [8]. Please note that with regards to the demagnetization evaluation at lower temperatures, down to $-40^{\circ} \mathrm{C}$, FE modelling has been performed but due to a similar impact on the two rotor types, the results have not been covered in this paper. The BEMF prior to and after the demagnetization test has been measured and compared in Fig. 15, where no sign of demagnetization is observed. For a more detailed evaluation of the demagnetization performance of the single piece and the fir tree based rotor designs, the loss of BEMF (as a result of demagnetization) has been calculated by FE 3D (the demagnetized regions in the magnets were defined as air, [8]), and the results are reported together with those from the prototype measurements in Fig. 16. From Fig. 16 and confirming the findings in [19], it is realized that due to $3 \mathrm{D}$ effects (for both rotor designs) the demagnetization performance of the $39 \mathrm{~mm}$ stack model is, significantly, superior to that of the nominal design with $195 \mathrm{~mm}$ stack length. Furthermore and confirming the predictions in Section III. B, it can be realized that, except for the local and rather negligible demagnetization risk at light faults, the demagnetization resistance of the single piece design may outperform that of the fir tree design option.

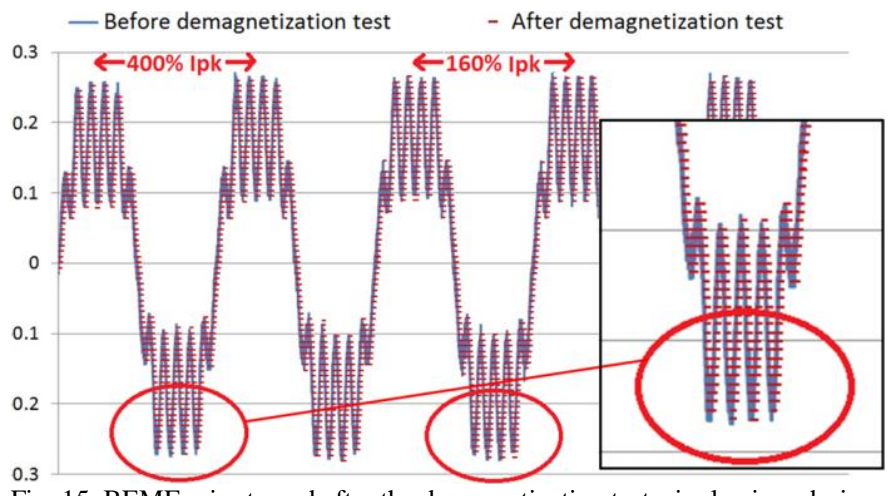

Fig. 15. BEMF prior to and after the demagnetization test, single piece design. 
II 3D FE, $5 \times 39 \mathrm{~mm}$ ㅁ 3D FE, $39 \mathrm{~mm}$ 心 Prototype, 39 mm

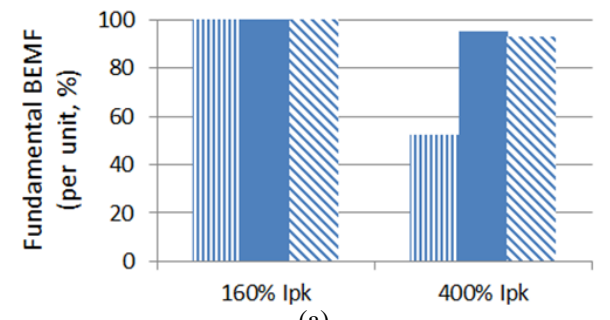

(a)

III 3D FE, $5 \times 39 \mathrm{~mm}$ = 3D FE, $39 \mathrm{~mm}$ ง Prototype, $39 \mathrm{~mm}$

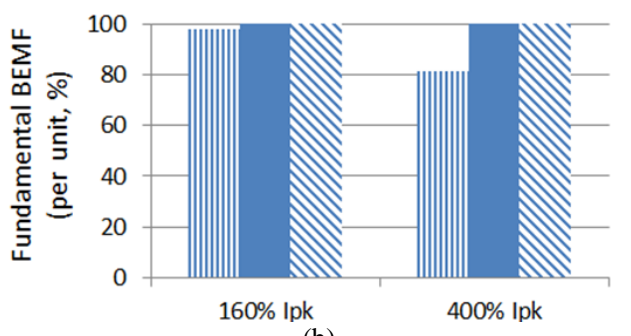

(b)

Fig. 16. Loss of BEMF fundamental component due to demagnetization. (a) Fir tree based rotor design. (b) Single piece rotor design.

\section{V.DISCUSSIONS}

Based on the analysis provided in the previous sections, the fir tree design may outperform the single piece design in terms of the power density and efficiency. However, the extra components in the fir tree alternative are likely to increase the manufacturing and material cost associated with this type of design, as a result of which, the single piece alternative might become more competitive in terms of the performance per unit cost.

This paper has compared the performance of the two alternative topologies against the same and specific requirements for a high-speed, high-power traction motor. Considering a different set of requirements, which are more suited to the single piece design, the performance gap between the two topologies is likely to reduce, which would, further, improve the performance per cost index of the single piece design. It is estimated that a motor requiring a lower top speed would favor the single piece design due to smaller centrifugal forces, as a result of which narrower bridge, thereby, lower flux leakage and larger torque densities may become achievable.

With respect to the fine single piece rotor design features, namely the thin lateral branches in Fig. 1(a), it should be noted that whilst these features proved to enhance the single piece rotor design performance, they may add to the manufacturing complexity and costs. Furthermore, the influence of the material deterioration due to the machining process has to be accounted for. As a result, for a volume production these features might need to be, partially or fully, compromised, leading to additional loss of the electromagnetic performance.

Furthermore, with respect to the magnet volume, it should be noted that whilst enlarging the magnets might increase the magnetic loading and enhance the electromagnetic performance, it is limited by the peak stress in the rotor pole via the centrifugal force proportionality, (1), $m$ corresponding to the magnet and rotor mass per pole, $r$ the radius of the center of gravity, and $\omega$ the angular velocity of rotor. As a result, whilst for the given design constraints in this paper, i.e. the rotor top speed and radius in Tables I and II, the allocated magnet volume cannot be further increased (as the stress levels are, already, higher than the fir tree equivalent design and close to the maximum limit of the steel), it is envisaged that for designs with a lower top speed, a radially longer magnet and a higher magnetic loading might be achievable.

$$
\sigma \propto m . r . \omega^{2}
$$

\section{CONCLUSION}

In this paper, a high power density- high speed traction motor design using ferrite magnets, and based on a single piece spoke type rotor topology has been presented. The design has been optimized following a stress constrained mass minimization procedure, combined with a maximization of the electromagnetic torque density. The solution is compared against an alternative spoke type design based on a two part fir-tree rotor configuration, which has been optimized (as part of an earlier disclosure) for the same geometrical and output requirements. Based on the analyses, the fir tree rotor outperforms the single piece option in terms of the power density and the efficiency due to a better utilization of the magnets, while, the latter demonstrates better demagnetization performance due to a higher leakage in the direct axis (d-axis) region. It should be noted that the addressed single piece design has been pushed to its ultimate magneto-structural limits to assess the maximal potential of such a design vs. a fir tree alternative; therefore, in practice, a larger performance gap between the two designs can be envisaged. Due to the fewer components involved with the single piece design, this option may match the fir tree version in terms of the cost per output power, when design for high volume is considered. Furthermore, reducing the top speed requirement may improve the single piece design competitiveness, as larger magnets and, therefore, higher torque densities may become achievable. This paper, for the first time, demonstrates (qualitatively and quantitatively) that the choice of a mechanical configuration for a spoke type rotor design might have significant influences on the electromagnetic performance. On this basis, the key design guidelines have been provided to explain these influences, and to enable the designers to utilize each alternative solution to its optimal capacity.

\section{ACKNOWLEDGMENT}

The authors gratefully acknowledge the support from Jaguar Land Rover and Tata Steel under the Evoque-E project.

\section{APPENDIX I}

An illustrative cost comparison of the two rotor topologies has been provided in Fig. 17. In Fig. 17, the rotor yoke material of the fir tree based design is assumed to be Nitornic 50, [21], while the additional assembly costs include the extra work and features required to affix the yoke and the poles in the fir tree based rotor, and is estimated for a high volume units production (the values in Fig. 17 are intended for illustration purposes, and the detailed aspects and grounds of the costing are outside the scope of this paper). 
घ Ferrite magnets $\square$ Rotor poles and yoke $\square$ Extra assembly costs due to additional parts

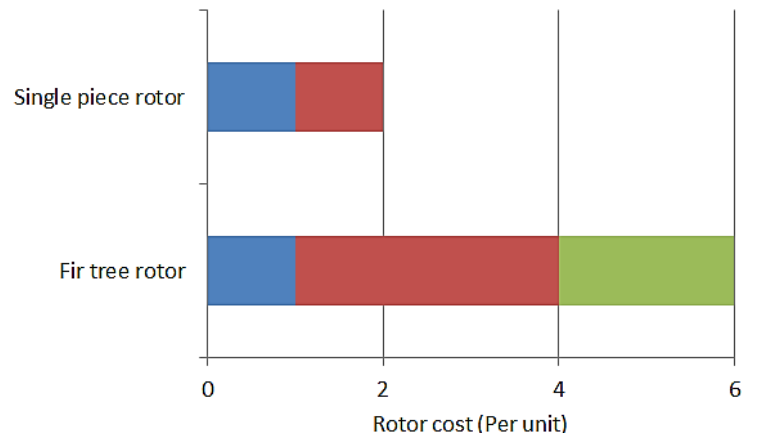

Fig. 17. Cost comparison between the two spoke type rotor alternatives.

\section{APPENDIX II}

To optimize the single piece rotor structural design, a topology optimization technique based on a Solid Isotropic Material with Penalization (SIMP) method, [26, 27], has been applied. This technique is, widely, used in areas such as civil and structural engineering, and is based on an allocation of structural parameters (such as stiffness and mass) to each finite element domain, which are then governed by optimization functions, including the objectives and the constraints.

A practical approach to implement a topology optimization is the so called stress constrained mass minimization method, based on which the mass of the structure, i.e. rotor, is minimized such that the stress in any finite element domain does not exceed the yield stress of the corresponding material, [28]. On this basis, the objective function is defined as (2), and it is constrained by the Hooke's law (3.1). In (3.1) the stress, $\sigma_{i}$, and strain, $\mathrm{x}$, are related by the stiffness matrix, $K$, which itself is a function of the mass density, $\rho$, the Young's modulus, $E_{0}$, and the Poisson's ratio, $\vartheta$, associated with each finite element domain, (3.2). Furthermore, assuming isotropic laminations, the stress, $\sigma_{i}$, can be represented by the Von Mises stress, as defined in (3.3), while $x, y, z$ represent the Cartesian dimensions .

$$
\begin{gathered}
\text { Minimize } m(\rho)=\sum_{1}^{N} \rho_{i}, \quad \rho_{i}<1 \\
\text { Constraint: } f=K \cdot x, \quad f\left(\sigma_{i}\right)<\sigma_{\text {yield }} \\
K\left(\rho, E_{0}, \vartheta\right)=\sum_{i=1}^{N} \rho_{i} \cdot k_{i}\left(E_{0}, \vartheta\right) \\
\sigma_{i}=\sqrt{\left\{\left(\sigma_{x}-\sigma_{y}\right)^{2}+\left(\sigma_{x}-\sigma_{z}\right)^{2}+\left(\sigma_{y}-\sigma_{z}\right)^{2}\right\} / 2}
\end{gathered}
$$

A solution from the rotor topology optimization, further constrained by the electromagnetically defined generic patterns in Section III.A, has been provided in Fig. 18, where a sample of the finite element network and the local structural parameters has been illustrated.

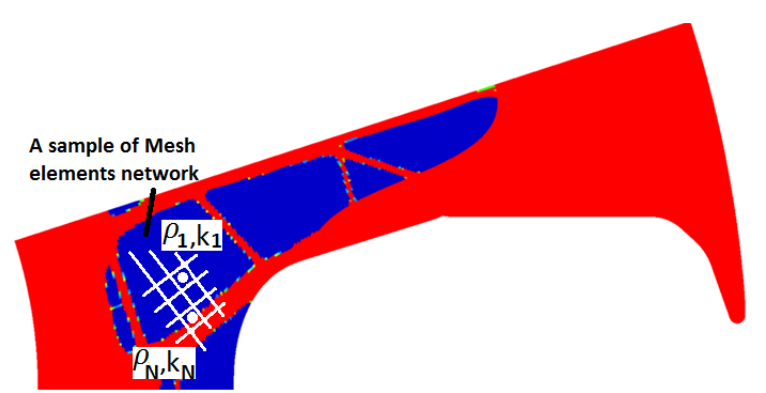

Fig. 18. Illustration of the stress-constrained mass minimization technique, employed for optimizing the single piece rotor design topology.

\section{REFERENCES}

[1] J. D. Santiago, H. Bernhoff, B. Ekergårdet, et al., "Electrical Motor Drivelines in Commercial All Electric Vehicles: a Review", IEEE Trans. Vehicular. Tech., vol. 61, no. 2, pp 475-484, Feb. 2012.

[2] T. A. Burress, S. L. Campbell, C. L. Coomer, et al., "Evaluation of the 2010 Toyota Prius Hybrid Synergy Drive System,'” Oak Ridge Nat. Lab., Oak Ridge, TN, USA, ORNL/TM-2010/253, Mar. 2011.

[3] Y. Sato, S. Ishikawa, T. Okubo, et al., "Development of High Response Motor and Inverter System for the Nissan leaf electric Vehicle", SAE Technical Paper 2011-01-0350, Apr. 2011.

[4] R. H. Staunton, T.A. Burress, and L.D. Marlino, "Evaluation of 2005 Honda Accord Hybrid Electric Drive System," Oak Ridge Nat. Lab., Oak Ridge, TN, USA, ORNL/TM-2006/535, Sep. 2006.

[5] J. D. Widmer, R. Martin, and M. Kimiabeigi, "Electric vehicle traction motors without rare earth magnets," Sustainable Materials and Technologies (Elsevier), Feb 2015.

[6] D. Dorrel, L.Parsa, and I. Boldea, "Automotive Electric Motors, Generators, and Actuator Drive Systems With Reduced or No Permanent Magnets and Innovative Design Concepts,' IEEE Trans. Ind. Electron., vol. 61, no. 10, Oct. 2014.

[7] S. J. Galioto, P. B. Reddy, A. M. EL-Refaie, "Effect of Magnet Types on Performance of High Speed Spoke Interior Permanent Magnet Machines Designed for Traction Applications," in Proc. IEEE ECCE, Sep. 2014, pp. 4513 - 4522

[8] M. Kimiabeigi, J. D. Widmer, R. Long, Y. Gao, J. Goss, R. Martin, T. Lisle, J.M. Soler Vizan, A. Michaelides, and B. Mecrow, "High Performance Low Cost Electric Motor for Electric Vehicles Using Ferrite Magnets," IEEE Trans. Ind. Electron., vol. 63, no. 1, pp.113122, Jan 2016.

[9] M. Barcaro and N. Bianchi, "Interior PM machines using ferrite to replace rare-earth surface PM machines," IEEE Trans. Ind. Appl., vol. 50, no. 2, pp. 979-985, Mar./Apr. 2014.

[10] S. Morimoto, S. Ooi, Y. Inoue, and M. Sanada, "Experimental Evaluation of a Rare-Earth-Free PMASynRM With Ferrite Magnets for Automotive Applications," IEEE Trans. Ind. Electron., vol. 61, no. 10 , Oct. 2014

[11] B. Boazzo, A. Vagati, G. Pellegrino, E. Armando, and P. Guglielmi, "Multipolar Ferrite-Assisted Synchronous Reluctance Machines: A general design approach," IEEE Trans. Ind. Electron., vol. 62, no. 2, pp. 832-845, Feb. 2015.

[12] H. Cai, B. Guan, and L. Xu, "Low-cost ferrite PM-assisted synchronous reluctance machine for electric vehicles," IEEE Trans. Ind. Electron., vol. 61, no.10, pp.5741-5748, Oct. 2014.

[13] H.-J. Kim, D.-Y. Kim, and J.-P. Hong, "Structure of concentrated-flux type interior permanent-magnet synchronous motors using ferrite permanent magnets," IEEE Trans. Magn., vol. 50, no. 11, Nov. 2014.

[14] Y. Burkhardt, A. Spagnolo, P. Lucas, et al., "Design and analysis of a highly integrated 9-phase drivetrain for EV applications," International Conference on Electrical Machines (ICEM), Sep 2014, pp. $450-456$.

[15] S. I. Kim, J. Cho, S. Park, T. Park, and S. Lim, "Characteristics comparison of a conventional and modified spoke-type ferrite magnet motor for traction drives of low-speed electric vehicles," IEEE Trans. Ind. Appl., vol. 49, no. 6, pp. 2516-2523, Dec. 2013.

[16] W. Fei, W. Liang, and P. C. K. Luk, "Influence of magnet layer number on electromagnetic performance of ferrite interior permanent magnet synchronous machine", International Conference on Electrical Machines and Systems (ICEMS), Oct 2014, pp. 1 - 7. 
[17] W. Zhao, T. A. Lipo, and B. I. Kwon, "Comparative study on novel dual stator radial flux and axial flux permanent magnet motors with ferrite magnets for traction application," IEEE Trans. Magn., vol. 50, no. 11, pp. 1-4, Nov. 2014.

[18] K. Chiba, S. Chino, M. Takemoto, and S. Ogasawara, "Fundamental analysis for a ferrite permanent magnet axial gap motor with coreless rotor structure," $15^{\text {th }}$ Int. Conf. in Electrical Machines and Systems (ICEMS), pp. 1-6, Oct. 2012.

[19] M. Kimiabeigi, J. D. Widmer, R. Long, Y. Gao, J. Goss, R. Martin, T. Lisle, J.M. Soler Vizan, A. Michaelides, and B. Mecrow, "3D Modelling of Demagnetization and Utilization of Poorer Magnet Materials for EV/ HEV Applications,” IEEE Trans. Energy. Convers., Early access publication, Apr 2016.

[20] A. Sarikhani, and O. A. Mohammed, "Demagnetization Control for Reliable Flux Weakening Control in PM Synchronous Machine," IEEE Trans. Energy. Convers., vol. 27, no. 4, pp. 1046-1055, Dec. 2012.

[21] M. Kimiabeigi, J. D. Widmer, R. Long, Y. Gao, J. Goss, R. Martin, T. Lisle, J.M. Soler Vizan, A. Michaelides, and B. Mecrow, "On Selection of Rotor Support Material for a Ferrite Magnet Spoke Type Traction Motor," IEEE Trans. Ind. Appl., vol. 52, no. 3, pp.22242233, May/ June 2016.

[22] "Permanent Magnet Rotor for High Speed Motors and Generators," by Carl J. Heyne, Granted on May 1986, US4588914 A, Available: http://www.google.com.ar/patents/US4588914.

[23] B. A. Welchko, T. M. Jahns, W. L. Soong, and J. M. Nagashima, "IPM Synchronous Machine Drive Response to Symmetrical and Asymmetrical Short Circuit Faults, " IEEE Trans. Energy. Convers., vol. 18, no. 2, pp. 291-298, June. 2003.

[24] P. H. Mellor, R. Wrobel, and D. Holliday, "A computationally efficient iron loss model for brushless ac machines that caters for rated flux and field weakened operation." In Proc. IEEE Int. Electric Machines and Drives Conf. IEMDC '09, pages 490-494, 2009.

[25] 1. J. Goss, P. H. Mellor, R. Wrobel, D. A. Staton, and M. Popescu, "The design of AC permanent magnet motors for electric vehicles: a computationally efficient model of the operational envelope," in 6th IET International Conference on Power Electronics, Machines and Drives (PEMD 2012), 2012, pp. B21-B21.

[26] Browne, Philip A. "Topology Optimization of Linear Elastic Structures." PhD Thesis. University of Bath, 2013, Available: http://www.met.reading.ac.uk/ vb904302/browne_phd.pdf.

[27] M.P. Bendsoe and O. Sigmund. Topology Optimization: Theory, Methods, and Applications, Springer, 2003.

[28] E. Lee, K.A. James, J.R.R.A. Martins, "Stress-constrained topology optimization with design-dependent loading," Struct Multidiscip Optim., 46 (2012), pp. 647-661, doi:10.1007/s00158-012-0780-x.

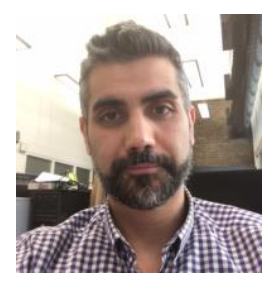

Mohammad Kimiabeigi received the M.S degree in electric power engineering from Royal Institute of Technology, Sweden, in 2008, and is currently working toward $\mathrm{PhD}$ at Newcastle University, UK. $\mathrm{He}$ has been a research engineer at $\mathrm{ABB}$ competence center, Sweden, Siemens Wind Power, Denmark, and Siemens Wind Power competence center, UK. Mr Kimiabeigi holds 12 granted European and U.S patents, 20 filed patent applications, and 15 journal and peer reviewed conference publications. During his career, he has been a lead design engineer for $R \& D$ projects in excess of $£ 10 \mathrm{M}$, and is currently a co-investigator in number of research grants, with a total value of $£ 1.2 \mathrm{M}$, to develop traction motors for land, marine, and aerospace applications.

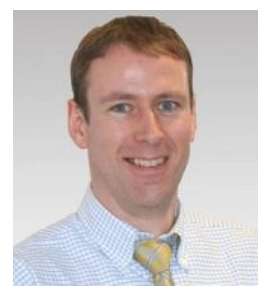

Raymond Long has over 19 years of experience supporting engineering design and development projects across a variety of industries (Automotive, Building, Lifting \& Excavating and Rotating Machinery). He has a broad skill base including engineering design and manufacture combined with $\mathrm{CAD}$ and $\mathrm{CAE}$ on a wide range of customer support and research projects. He uses a number of industry standard $\mathrm{CAD}$ and $\mathrm{CAE}$ tools to develop the performance of components and assemblies (Hyper Works, CATIA, ABAQUS, NASTRAN, LS-Dyna and PAM-Stamp). Most recently through collaborative development projects supporting the applications of electrical steels, he has been named as co-inventor on two pending patent applications.

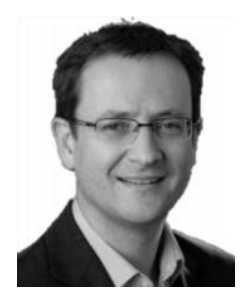

James D. Widmer has a PhD in the design of electrical machines from Newcastle University, U.K. He joined Newcastle University in 2009 from a senior post in the aerospace industry. He is responsible for the "Centre for Advanced Electrical Drives," Newcastle University which works with industry partners to convert academic research into world-class products. His research interests include high-efficiency permanent magnet machines and rare-earth magnet-

free motor topologies.

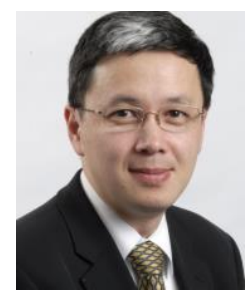

Yi Gao received a $\mathrm{PhD}$ in 1992 for research into fatigue of metal matrix composites (MMCs) from the University of Nottingham, UK. Currently, he is a technical specialist at R\&D of Tata Steel in the field of metal and weld fatigue. His technical interest covers durability CAE assessments of automotive and other land transport vehicles, linking manufacturing effects to structural durability, and integrity of offshore pipelines. For the past few years, he has led Tata Steel's efforts in structural and durability design of electrical steel cores in high-performance electric machines. Dr Gao is a Chartered Engineer and a Fellow of the Institution of Mechanical Engineers. 